\title{
Compliance efficacy and patient satisfaction with two litre polyethylene glycol ascorbic acid for colonoscopy preparation in a outreach rural setting
}

\author{
David J de Villiers, Paul A Goldberg, Ursula Algar \\ Colorectal Unit, Department of Surgery, Groote Schuur Hospital, University of Cape Town, South Africa
}

Corresponding author: David J de Villiers (devilldj@gmail.com)

\begin{abstract}
Background: Annual surveillance of Lynch Syndrome patients from the rural Northern Cape Province of South Africa is conducted with a mobile colonoscopic unit. Excellent preparation of the colon is essential to detect small right sided lesions. We wished to evaluate a two litre polyethylene glycol (PEG) electrolyte solution containing ascorbic acid and sodium

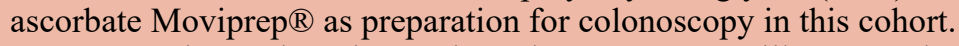

Methods: Six weeks prior to the colonoscopy surveillance week, a team travelled to the area to prepare the patients for colonoscopy. Patients were individually counselled on the importance of bowel cleansing and the use of Moviprep ${ }^{\circledR}$. Prior to their colonoscopy, subjects completed a product acceptability questionnaire. At the procedure, the quality of bowel preparation was assessed by a single individual (DJdV) using the Harefield cleansing scale grades; grades A or B were defined as good preparation and grades $\mathrm{C}$ or $\mathrm{D}$ as poor preparation.

Results: Sixty four of the 71 subjects seen on the preparation trip completed the questionnaire and took their Moviprep ${ }^{\circledR}$. The questionnaire responses showed that $53(83 \%)$ had used other colon preparations previously and $57(89 \%)$ would prefer Moviprep ${ }^{\circledR}$ for their next colonoscopy. Eighteen patients did not undergo colonoscopy due to time constraints. Forty-one of the 46 subjects $(89 \%)$ who underwent colonoscopy had successful colonic preparation 7 of whom received an extra litre of Moviprep due to stool based nursing assessment prior to colonoscopy. Side effects of nausea and hunger were occasionally troublesome but did not affect compliance.

Conclusion: When patients are pre-councelled, Moviprep ${ }^{\circledR}$ provides adequate colonic cleansing in $73 \%$ with the standard regimen and $89 \%$ after additional prep in subjects undergoing surveillance colonoscopy in a rural setting. Moviprep was tolerated well and $88 \%$ of subjects would choose the same preparation for their next colonoscopy.
\end{abstract}

\section{Introduction}

One of the factors that negatively affect polyp detection is an inadequately prepared colon. A cohort of individuals with Lynch Syndrome ( $h$ MLH1 mutation C1528T) undergo a surveillance colonoscopy in small rural hospitals where endoscopy is not usually available as part of an outreach project. There are major resource constraints within the region. The nearest routine colonoscopy service is between 600 and $1200 \mathrm{~km}$ away from where these high risk individuals live.

The only bowel preparation available previously in the region was an oral phosphate soda type preparation. There was some concern about this preparation because of the inability to ensure adequate fluid intake and pre-preparation fitness. We therefore sourced a four litre polyethylene glycol (PEG) solution, but compliance was an issue because of the large volume. The availability of a two litre PEG ascorbic acid solution may address both the safety and compliance concerns.

The aim of this study was to assess the efficacy and acceptability of a two litre preparation of PEG with ascorbic acid and ascorbate. The primary endpoint was the quality of colon preparation and the secondary endpoint was subject acceptability of the preparation.

\section{Methods}

The study was conducted in two main phases. This study was passed by the Research Ethics Committee of the University of Cape Town (HREC REF:249/2013).

\section{Phase one}

All known high risk individuals who require colonoscopic surveillance were identified. A one-week preparation road trip was undertaken into the western part of South Africa from 7 July 2013 until 12 July 2013. The team consisted of a professional nurse specialised in genetics, a genetics registrar, 
a professional endoscopy nurse, a representative of the Norgine, now Aspen, pharmaceutical company and a registrar in general surgery.

Fourteen towns were visited in the Northern Cape. Subjects received counselling on the importance of good bowel preparation for colonoscopy and each received an information sheet detailing the aim, methods and possible risks involved in this study in their home language.

Where subjects could not be seen in person, a family member or the primary health care worker was requested to convey the information. All subjects were given the choice between the standard bowel preparation namely Kleanprep ${ }^{\circledR}$, or using Moviprep ${ }^{\circledR}$ for the first time. During this session, it was made clear to the patient that Moviprep ${ }^{\circledR}$ is not an experimental colonic preparation and that it has been well proven and studied in its efficacy and side effect profile. This study aimed to look at the efficacy and patient opinion of Moviprep ${ }^{\circledR}$ in a rural setting. They all chose Moviprep ${ }^{\circledR}$.

Moviprep ${ }^{\circledR}$ includes a detailed instructional pamphlet. This pamphlet served as the standardised instruction during the counselling sessions. This aided informing subjects on dietary requirements the day prior to colonoscopy, extra clear fluid intake and instructions on mixing the product.

Each subject was given a choice on when to drink the two litres of Moviprep ${ }^{\circledR}$. Either as single dose two litres at $05 \mathrm{~h} 00$ the morning of the colonoscopy or a split dose, consisting of one litre Moviprep ${ }^{\circledR}$ the night prior to and the second litre the morning of the colonoscopy.

Informed consent was obtained from all subjects participating in the study which included consent for the use of Moviprep ${ }^{\circledR}$ as bowel preparation as well as completion of a product acceptability questionnaire.

\section{Phase two}

A week-long trip was undertaken from 26 August 2013 until 30 August 2013 to the Northern Cape, with a 19 member team. Four pre-planned destinations included: Upington, Nababeep, Garies and Vredendal Hospitals. Fully equipped endoscopy units were set up in each centre.

Questionnaires that assessed compliance, product satisfaction, side effect profile, and comparison to other preparation products were completed by the patients awaiting their colonoscopies.

Prior to colonoscopy, each subject's colonic cleansing was assessed by a nurse who inspected the stool consistency. Each subject noted to have particulate matter in his or her stool, was given an additional litre of Moviprep ${ }^{\circledR}$.

Every colonoscopy was evaluated and scored on cleanliness and quality of preparation by an investigator who was not doing the colonoscopy (DJdV). The scoring was done during the course of each endoscopy using a validated colonic preparation scoring system - The Harefield Cleansing Scale.

The Harefield Cleansing Scale divides the colon into six segments (rectum, sigmoid, descending-, transverse- and ascending colon and cecum). A grade ranging from A to D is awarded to each segment as follows:
$\mathrm{A}=$ all colon segments clean;

$\mathrm{B}=$ at least 1 segment with residual amounts of brown liquid or semisolid stool, which can easily be displaced or removed; $\mathrm{C}=$ at least 1 segment with only partially removable stool, preventing complete visualization; $\mathrm{D}=$ at least 1 segment which cannot be examined due to solid stool.

Grade A or B was considered as a good or successful cleansing. Grade C or D was considered a poor or failed colonic preparation. (Appendix C)

All data processing was done with the aid of Microsoft Office Excel 2007.

\section{Results}

\section{Phase one}

The counselling ratios of the cohort planned to undergo colonoscopy are shown as Phase 1 in Figure 1.

During the initial phase of the study, a total of 71 boxes of Moviprep ${ }^{\circledR}$ were distributed to subjects. Sixty-eight percent were directly counselled and consented by DJdV and $23 \%$ received their counselling indirectly from a family member who attended the counselling session, or a professional nurse known to the patient. Ten percent of the subjects had their preparation delivered to the local clinic but it was not possible to provide personalised instruction. None of these seven subjects arrived for their colonoscopies during the second phase of the study.

\section{Phase two}

Figure 1 Phase 2 details the questionnaire completion, drop out rate, and the quality of the preparation of colonscopy related to the preparation methods of administration and type of counselling. Sixty-four subjects (90\%) received Moviprep ${ }^{\circledR}$ as their colonic preparation and had completed the questionnaire. Due to logistic constraints at one of the venues, $28 \%$ of colonoscopies could not be performed. Of the 46 patients who had their colonoscopies performed, $89 \%$ were graded A or B (Good) which included 7 of the 9 patients who required an additional litre of prep. Eleven percent were grade $\mathrm{C}$ and D (Poor) (Figure 1).

Thus, of the 41 patients who had good colonic preparation, $26 / 41(63 \%)$ received direct counselling from the investigator (DJdV) and 15/41 (37\%) indirect counselling from either a counselled family member or a professional nurse. Of the 5 patients who failed their colonic preparation, 4/5 were counselled directly and $1 / 5$ received indirect counselling.

When comparing single or split dose preparation of Moviprep ${ }^{\circledR}, 80 \%$ of the 41 patients who had successful colonic preparation had used the single dose method and $20 \%$ had used the split dose method. All the patients who had failed their colonic preparation had used the single dose method.

Of the 64 who completed the questionnaire $28 \%$ reported an unpleasant taste and $72 \%$ reported a pleasant taste. Eightyeight percent found Moviprep ${ }^{\circledR}$, as a product, easy to prepare and all but one reported that they had followed the instructions regarding diet and fluid intake during the preparation process. 


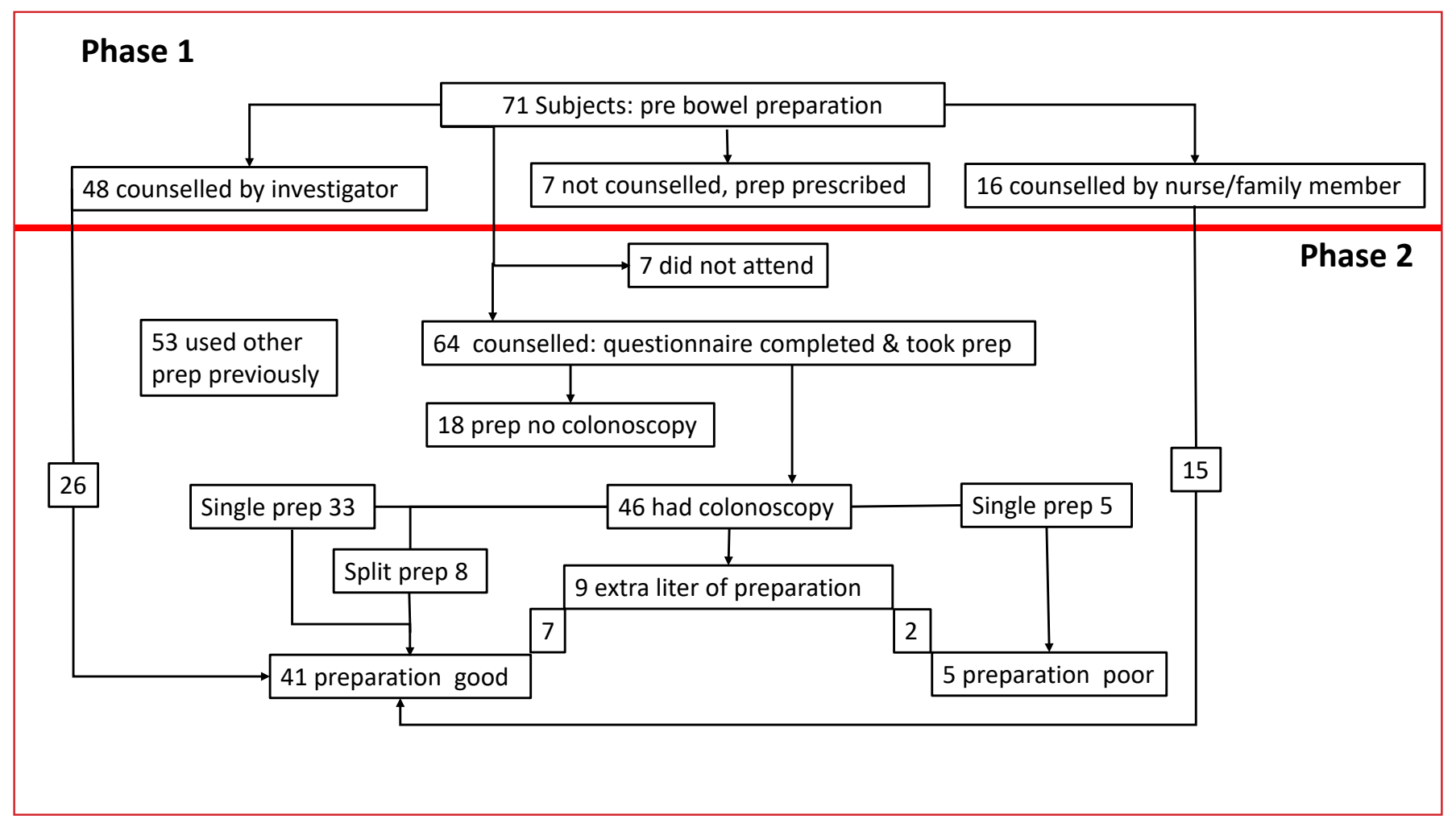

Figure 1. The target colonscopy cohort, counselling, attrition rate, preparation type and quality of preparation consort diagram

The side effect profile was found to be similar to most bowel preparation regimes. This included nausea and/or vomiting, abdominal cramps and a feeling of "hunger" during the preparation period. Subjects were asked to rate each possible adverse reaction or event on a scale of 1 to 5 . One being the least severe, and 5 most severe. Of the 64 patients who had completed a questionnaire, $6 \%$ experienced nausea graded at $5 / 5$. Abdominal cramps were experienced at a rating of in $11 \%$ of subjects and graded as $5 / 5$ in $5 \%$ of subjects. The main adverse event experienced by subjects was the sensation of "hunger" during the preparation phase; $17 \%$ rated hunger at $5 / 5$ and $23 \%$ rated it at $2 / 5$.

Of the 64 patients, $83 \%$ had used a colonic cleansing preparation in the past. None of these patients had ever used Moviprep ${ }^{\circledR}$ as colonic preparation prior to this study. Of the 53 patients, who had used a different type of colonic preparation in the past, 91\% preferred using Moviprep ${ }^{\circledR}$ as their colonic preparation in the future. When asked whether or not Moviprep ${ }^{\circledR}$ would be considered for future colonic preparation, $89 \%$ answered yes.

\section{Discussion}

A lot of emphasis is placed on bowel preparation prior to colonoscopy with good reason, as stipulated before. The patients in this cohort cannot afford missing out on a single surveillance colonoscopy, especially not due to poor bowel cleansing.

Several studies established that in preventing colorectal cancer, colonoscopy is less effective in the proximal compared to the distal colon. Reasons for this might be poor colon preparation prior to colonoscopy or the fact that polyps in the proximal colon tend to be more difficult to detect. ${ }^{1-3}$ Without proper colonic cleansing, a complete and thorough investigation is not possible, and there is a higher risk of patient discomfort and possible complications related to the procedure itself.

In this study population, colonoscopy was performed in patients at high risk of developing colon cancer and the lesions are mostly encountered on the right side of the colon. This emphasises the need for an adequately prepared colon even more. These patients live in a rural part of South Africa and are screened annually by a visiting colonscopy service. It is thus very important, in this rural setting, that every colonoscopy is preceded by optimal bowel cleansing.

During this study we offered a cohort of patients an alternative colonic preparation to what they had used in the past. This product is marketed as being half the usual volume, two litres compared to four litres, as well as having a more pleasant taste. This should make the likelihood of the patient completing his/her preparation regime with Moviprep ${ }^{\circledR}$ much greater.

In a systematic review by van Rijn et al., they reviewed polyp miss rate looking at both polyp size and polyp type. A total of 465 colonoscopies were reviewed. ${ }^{6}$ Adenoma miss rate was $2.1 \%$ for polyps larger than $10 \mathrm{~mm}, 13 \%$ for adenomas $5-10 \mathrm{~mm}$ and $26 \%$ for adenomas of $1-5 \mathrm{~mm}$. Polyps larger than $10 \mathrm{~mm}$ are rarely missed at colonoscopy, but the miss rate increases significantly as the polyp size decreases. ${ }^{6}$ In their review of the literature, they found that 
one in five polyps is missed at colonoscopy. Larger polyps are less likely to be missed, but some big adenomas might be overlooked. One in four adenomas (1-5 mm) may be missed. Unfortunately the number of studies looking at this specific topic is small. ${ }^{6}$

Bressler et al. reviewed the miss rate of right sided colon cancer in 4920 patients. They identified 4920 persons with a new diagnosis of right-sided colon cancer, of whom 2654 (54\%) had had at least 1 colonoscopy within 3 years of their admission for surgical resection. Most (96\%) had had their most recent colonoscopy up to 6 months before admission, seen as detected cancers. However, 105 patients (4\%) had their most recent colonoscopy between 6 and 36 months before admission to the hospital and viewed as missed cancers. ${ }^{7}$

Of the 71 patients approached for this study regarding the use of Moviprep ${ }^{\circledR}, 64$ were enrolled in the study and 46 colonoscopies were evaluated for colonic cleansing. Data clearly shows that Moviprep ${ }^{\circledR}$ can be used for colonic preparation in the rural setting with great success using direct counselling. This was proven with successful cleansing in $89 \%$ of all scoped patients, taking into consideration that of the 41 patients who had successful cleansing, 7 were given an additional litre of prep prior to colonoscopy. A similar percentage of patients were satisfied with Moviprep ${ }^{\circledR}$ and would prefer using it in the future for colonic preparation.

Colonic preparation will never be viewed as a convenient and easy process. What we essentially induce in our patients is diarrhoea with nausea and vomiting in some cases. With this being said, one can understand that some patients find it very difficult to complete a course of colonic preparation despite the risk of an incomplete colonoscopy. The main drive behind this study was to see if we can offer patients, in this study group, an alternative to what they are used to. While doing this, we have proven the product to be effective, even in a rural community with minimal resources.

\section{Conclusion}

Moviprep ${ }^{\circledR}$ can effectively be used in the rural setting for bowel cleansing with proven patient satisfaction.

\section{Funding disclaimer}

Norgine, the marketers of Moviprep ${ }^{\circledR}$,provided the funding for both the preparation and counselling trips.

\section{REFERENCES}

1. Lakoff J, Paszat LF, Saskin R, et al. Risk of developing proximal versus distal colorectal cancer after a negative colonoscopy: a population based study. Clin Gastroenterol Hepatol. 2008;6:1117-2.

2. Singh H, Nugent Z, Mahmud SM, et al. Predictors of colorectal cancer after negative colonoscopy: a population-based study. Am J Gastroenterol. 2010;105:663-73.

3. Baxter NN, Goldwasser MA, Paszat LF, et al. Association of colonoscopynd death from colorectal cancer. Ann Intern Med. 2009;150:1-8.

4. Arora $\mathrm{M}$, et al. A critical evaluation and a search for the ideal colonoscopic preparation. Clin Res Hepatol Gastroenterol. Oct 2012.

5. Lorenzo-Zúñiga $\mathrm{V}$, et al. Preparation for Colonoscopy: Types of scales and cleaning products. Pubmed v77n1, Jan 2001.

6. Van Raij JC, Reitsman JB, Stoker J, at al. Polyp miss rate determined by tandem colonoscopy: A systematic review. Am J of Gastroenterology. 2006;101:343-50.

7. Bressler B, Paszat LF, et al. Colonoscopic miss rate of right sided colon cancer: A population based analysis. Gastroenterology. 2004;127:452-6 